The International Journal Of Engineering And Science (IJES)

|| Volume || 5 || Issue || 11 || Pages || PP 48-57 || 2016 ||

ISSN (e): $2319-1813 \operatorname{ISSN}(\mathrm{p}): 2319-1805$

\title{
Head Loss Estimation for Water Jets from Flip Buckets
}

\author{
Cuneyt Yavuz ${ }^{1}$, Ali E. Dincer ${ }^{2}$, Ismail Aydin ${ }^{3}$ \\ ${ }^{1,2}$ Ph.D. Candidate, Water Resources Lab., Dept. of Civil Engineering, Middle East Technical University, \\ 06800, Çankaya/Ankara, Turkey. \\ ${ }^{3}$ Professor, Hydromechanics Lab., Dept. of Civil Engineering, Middle East Technical University, 06800,
}

Çankaya/Ankara, Turkey.

\begin{abstract}
Water jet issued from flip bucket at the end of the spillway of a dam can be a threat for the stability and safety of the dam body due to subsequent scour at the impingement point. However, a strong jet from the flip bucket interacts with the surrounding air and develops into an aerated turbulent jet while the jet impact and scouring effect is reduced significantly. Aeration of the jet, at the same time, cause head losses along the trajectory. An experimental study is conducted to measure the trajectory lengths and investigate the effect of water depth in the river on the dynamic pressures acted on the river bed. The trajectory lengths with and without air entrainment are calculated using empirical equations and compared with the measurements. Head losses due to air entrainment are determined using the difference of the trajectory lengths with and without aeration, based on the projectile motion theory. Numerical simulation of the flow over the spillway, along the flip bucket and the jet trajectory is made and the results are compared with the experimental data. It is observed that trajectory lengths obtained from experiments, numerical simulation and empirical formulas are comparable with negligible differences. This allows us to combine alternate approaches to determine the trajectory lengths with and without air entrainment and estimate the head losses accordingly.
\end{abstract}

Keywords: Water Jet, Flip Bucket, Impact Assessment, Trajectory Length, Jet Dispersion, Numerical Method

Date of Submission: 10 November $2016 \longrightarrow$ Date of Accepted: 18 November 2016

\section{I.INTRODUCTION}

Reports of investigations of jets issued from a flip bucket can be found in French literature between 1930s and 1950s [1], [2], [3], [4]. These studies were conducted on prototype dams as reported in the observations of Maitre and Obolensky [5]. Flip buckets are used to dissipate energy of water coming from the spillway especially for high flow velocities. Flip buckets can be designed in various shapes and scales according to the geological and economic circumstances affecting the relative curvature, deflection angles, take-off angles and other components that are in operation. There are only a few guidelines available to standardize the design of flip buckets [6]. Heller et al. [7] considered the 2-D ski jump and they worked on the scale effects of the water jets and found that aerated water jets coming from the spillway required the approach flow depth of at least $40 \mathrm{~mm}$. They have examined the pressure distribution on the ski jumps for different takeoff angles. It was shown that the lower and upper jet trajectories have a different take-off angle from the bucket angle with parabolic jet trajectory depending on the Froude number and the approach flow depth. Mason [8] developed several empirical formulas to predict the scour depth and found that scour might be affected by the percentage of air entrainment present in the free jet. A new empirical equation to calculate the scour depth of aerated jets was also proposed based on experiments. It was found that the scour profiles caused by aerated jets are flatter than those caused by non-aerated jets.

In the present study, a hydraulic model [9] in the Hydromechanics laboratory of Middle East Technical University (METU) is used as the test basin (Fig. 1).

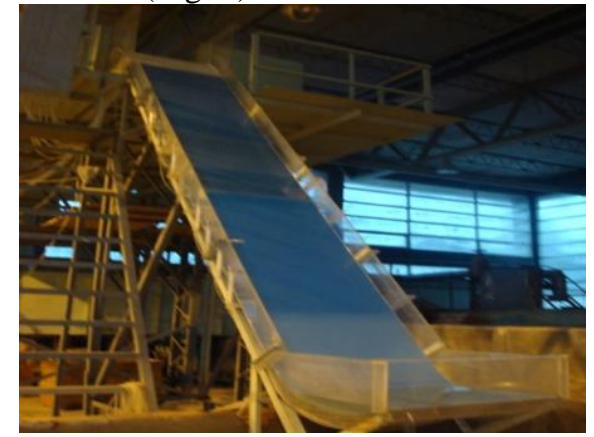


Fig. 1 Hydraulic Model

The physical model was constructed using Froude Similarity with a length scale of 1:25. Geometric elements of the spillway are shown in Fig. 2.

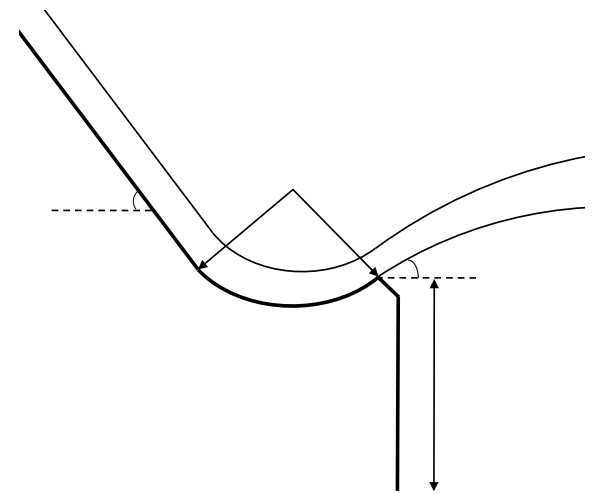

Fig. 2 Geometric elements of the Spillway and Flip Bucket

In order to assess the impact at the impingement area of the jet, 10 pressure transducers are used to record dynamic pressure distribution at the impact region (Fig. 3). Total pressures at the impingement area are measured for different tail water depths at the downstream of the flip bucket.

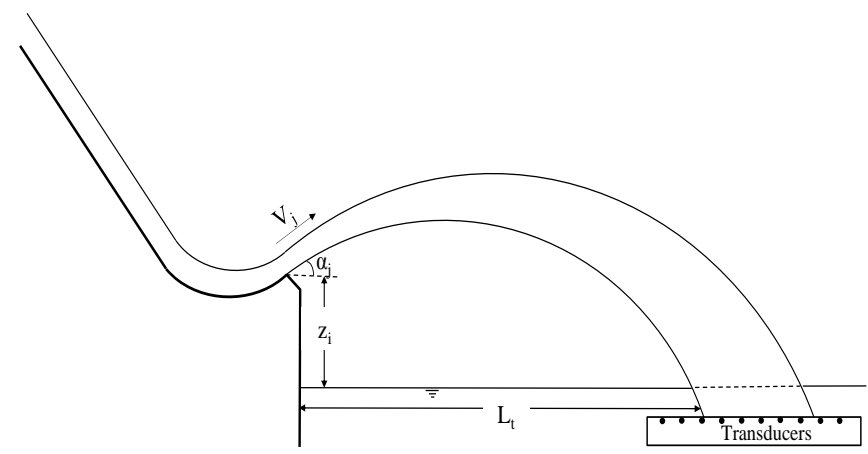

Fig. 3 Transducer arrangement and measured parameters

Additionally, trajectory lengths and jet velocities on the flip bucket lip are measured for all test cases. Trajectory lengths with and without air entrainment were also calculated using empirical formulas and measured jet velocities. Experimental data is evaluated to predict the head losses due to air entrainment.

\section{II.EXPERIMENTAL SETUP}

Experiments are performed for 6 different discharges [10]. Dynamic pressures at the impingement area are measured for 6 different tail water depths for all discharges. Thus, a total of 36 different pressure measurements are recorded. Jet velocity $\left(\mathrm{V}_{\mathrm{j}}\right)$ and the water depth $\left(\mathrm{y}_{0}\right)$ at the flip bucket lip and trajectory length $\left(\mathrm{L}_{1}\right)$ data measured from the test facility are given in Table 1.

Table 1 Data describing the test cases

\begin{tabular}{|l|l|l|l|}
\hline $\mathrm{Q}\left(\mathrm{m}^{3} / \mathrm{s}\right)$ & $\mathrm{y}_{0}(\mathrm{~m})$ & $\mathrm{V}_{\mathrm{j}}(\mathrm{m} / \mathrm{s})$ & $\left(\mathrm{L}_{1}\right)_{\mathrm{m}}(\mathrm{m})$ \\
\hline 0.07 & 0.035 & 7.86 & 5.49 \\
\hline 0.10 & 0.031 & 7.66 & 5.10 \\
\hline 0.13 & 0.027 & 7.41 & 5.04 \\
\hline 0.16 & 0.023 & 7.07 & 4.67 \\
\hline 0.19 & 0.019 & 6.58 & 4.07 \\
\hline 0.22 & 0.015 & 5.83 & 3.55 \\
\hline
\end{tabular}

Before starting the measurements, the discharge and tail water level are fixed for all test cases. Then, velocity of the jet, the flow depth and the horizontal throw distance to the point of impingement are measured. Velocity at the lip of the flip bucket is measured using a pitot tube. These measurements are repeated for each test case given in Table 1. Dynamic pressures are recorded by electronic transducers arranged along the impact region from the beginning to the end of the jet impingement line. Electronic signals from the pressure 
transducers are digitized by Data Acquisition system (DAQ) [11]. Dynamic pressures are recorded for a period of 180 seconds and digitized at $40 \mathrm{~Hz}$ frequency for every test case.

\section{III.JET TRAJECTORIES}

To predict non-aerated trajectory lengths the projectile motion theory is used. In this theory, the water jet is considered to be frictionless. The equation for the horizontal travel distance of the projectile motion is expressed as [12]

$\mathrm{L}_{\mathrm{t}}=\frac{\mathrm{V}_{\mathrm{j}} \cos \alpha_{\mathrm{j}}}{\mathrm{g}}\left(\mathrm{V}_{\mathrm{j}} \sin \alpha_{\mathrm{j}}+\sqrt{\left(\mathrm{V}_{\mathrm{j}} \sin \alpha_{\mathrm{j}}\right)^{2}+2 \mathrm{gz} \mathrm{z}_{\mathrm{i}}}\right)[1]$

where $\mathrm{L}_{\mathrm{t}}$ is the trajectory length for non-aerated jet, $\mathrm{z}_{\mathrm{i}}$ is the vertical drop from lip to tail-water level, $\mathrm{H}_{\mathrm{j}}$ is the velocity head of the jet at the bucket lip $\left(\mathrm{V}_{\mathrm{j}}^{2} / 2 \mathrm{~g}\right)$, $\alpha \mathrm{j}$ is the bucket lip angle (in degrees). The velocity head $\mathrm{H}_{\mathrm{j}}$ at the bucket lip can be calculated by accounting the head losses from reservoir up to the bucket lip. In this study, this is done by using the measured jet velocity at the lip of the bucket. Concerning the trajectory lengths with air entrainment, Kawakami [13] presented results of some field research on trajectories that are affected by the air resistance and defined a coefficient, $\mathrm{k}$ for the following equations

$\mathrm{L}_{1}=\left(\frac{1}{\mathrm{gk}^{2}}\right) \ln \left(1+2 \mathrm{kaV}_{\mathrm{j}} \cos \alpha_{\mathrm{j}}\right)$

where

$\alpha=\tan ^{-1}\left(k V_{j} \sin \alpha_{j}\right)$

andL $\mathrm{L}_{1}$ is the trajectory length considering air resistance, $\mathrm{k}$ is the aeration constant, $\mathrm{V}_{\mathrm{j}}$ is the velocity at the bucket lip.
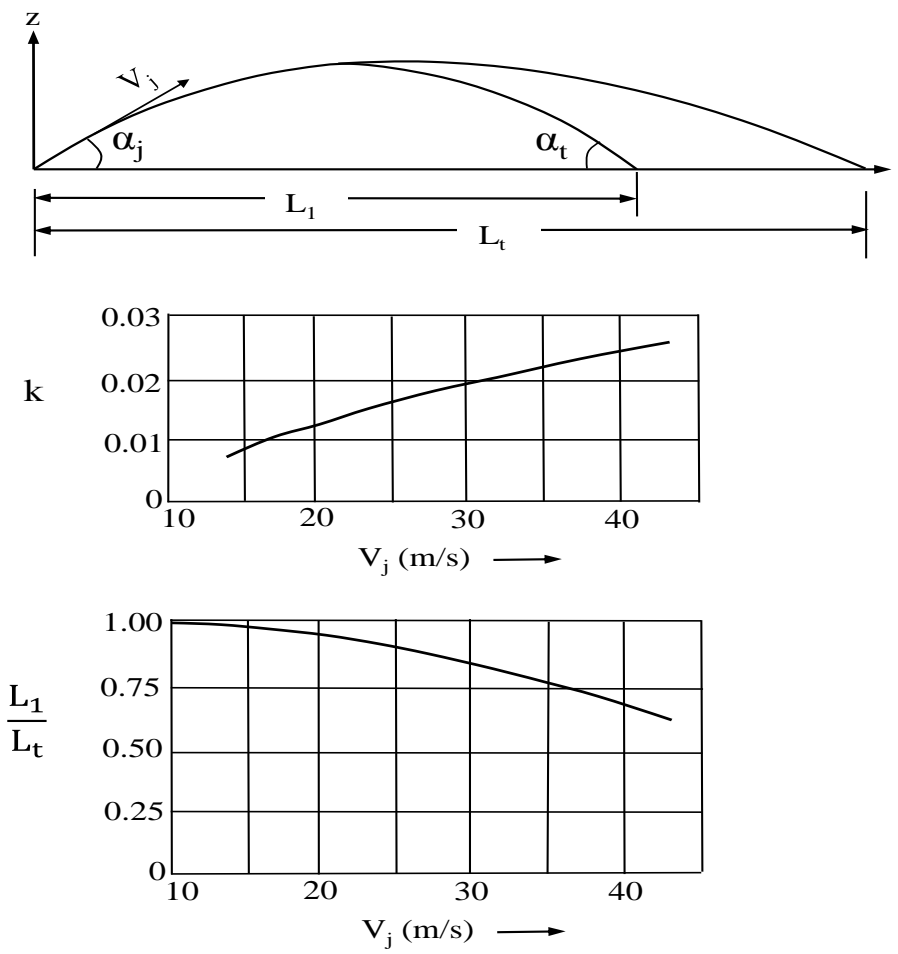

Fig. 4 Effect of air resistance on jet trajectory. [13]

Fig. 4 shows the experimental relationship between $V_{j}$ and $k$ and also $L_{1} / L_{t}$ values for variable $V j$, given by Kawakami [13], where $L_{t}$ is the throw distance without considering the air resistance, $\alpha_{t}$ represents the trajectory angle at the impingement point. It is observed that the effect of air resistance is small when $\mathrm{V}_{\mathrm{j}}$ is less than about $20 \mathrm{~m} / \mathrm{s}$ but, it reduces the throw distance by about $30 \%$ when the velocity is about $40 \mathrm{~m} / \mathrm{s}$.

Since the velocities measured in the present hydraulic model are small to use the graphs prepared by Kawakami, prototype velocities are calculated by using the Froude similarity law and appropriate comparisons are made.

\section{IV.NUMERICAL MODEL}

Numerical investigations can also be used to determine the characteristics of the flow in addition to experimental and empirical studies. Computational fluid dynamics (CFD) tools are used to solve the problem numerically. The commercial CFD code Flow 3D is used in the numerical study [14]. The Reynolds-Averaged Navier-Stokes (RANS) equations for an incompressible, Newtonian fluid are used in the numerical model. The $\mathrm{k}-\varepsilon$ model of turbulence [15] is used in the computation of Reynolds stresses. 
The CFD code uses fractional area volume obstacle representation (FAVOR), improved volume of fluid technique (VOF) and multi-block meshing to increase accuracy of the solution. In order to discretize the flow domain, structured grids are used by free gridding method. In this way, the time required for the grid generation and computation decreases considerably.

The spillway used for the experiments was constructed by using AutoCAD, commercially available CAD software [16]. Then the constructed model was imported to Flow-3D. Mesh sizes were taken as $5 \mathrm{~cm}$ in $\mathrm{z}$ direction and $10 \mathrm{~cm}$ in $\mathrm{x}$ direction in order to determine the wall shear stresses and slip effects between the boundary and the water correctly. For $3 \mathrm{~m}$ upstream of the spillway, reservoir levels were fixed for each case. Boundary conditions were defined as specified pressure with a constant water height at the flow inlet, symmetry at the top of the spillway and outflow at the downstream of the spillway. Time intervals were determined by considering the Courant-Friedrichs-Lewy (CFL) condition. For modeling turbulence k- $\varepsilon$ model was used and turbulent mixing length was dynamically computed. In order to save computational time, the computational model is assumed as 2-dimensional and the calculations were done in a 2D vertical plane.

\section{V.HEAD LOSS ESTIMATION}

The main aim of the water jet diverted into the air by a flip bucket is to reduce the energy of the high speed water coming from the spillway by creating jet dispersion. Dispersed jet entrains large amount of air and this reduces the jet velocity as a result of significant head losses. Head loss due to the air entrainment can be calculated from the difference between the trajectory lengths with and without air entrainment. The measured length in the hydraulic model is affected by the head losses due to air entrainment while the calculated length obtained from the projectile theory has no head loss effect since air entrainment is not accounted for. Energy for the two cases can be related as

$\mathrm{H}_{\mathrm{j}}=\mathrm{H}_{\mathrm{j} 2}+\mathrm{h}_{\mathrm{L}}$

where

$\mathrm{H}_{\mathrm{j}}\left(=\mathrm{V}_{\mathrm{j}}{ }^{2} / 2 \mathrm{~g}\right)$ is the jet head obtained from the jet velocity, $\mathrm{V}_{\mathrm{j} 1}$ is measured at the bucket lip, $\mathrm{H}_{\mathrm{j} 2}\left(=\mathrm{V}_{\mathrm{j} 2}{ }^{2} / 2 \mathrm{~g}\right)$ is the hypothetical jet head obtained from projectile theory using the measured trajectory length which is affected from head losses. $V_{j 2}$ is obtained from Eq. [1] by inserting the measured trajectory length, $L_{1}$ in place of $L_{t}$ in the equation. Then, the head loss due to air entrainment, $h_{L}$ is obtained from Eq. [4]. Various parameters related to projectile motion of the jet are defined in Fig. 5.

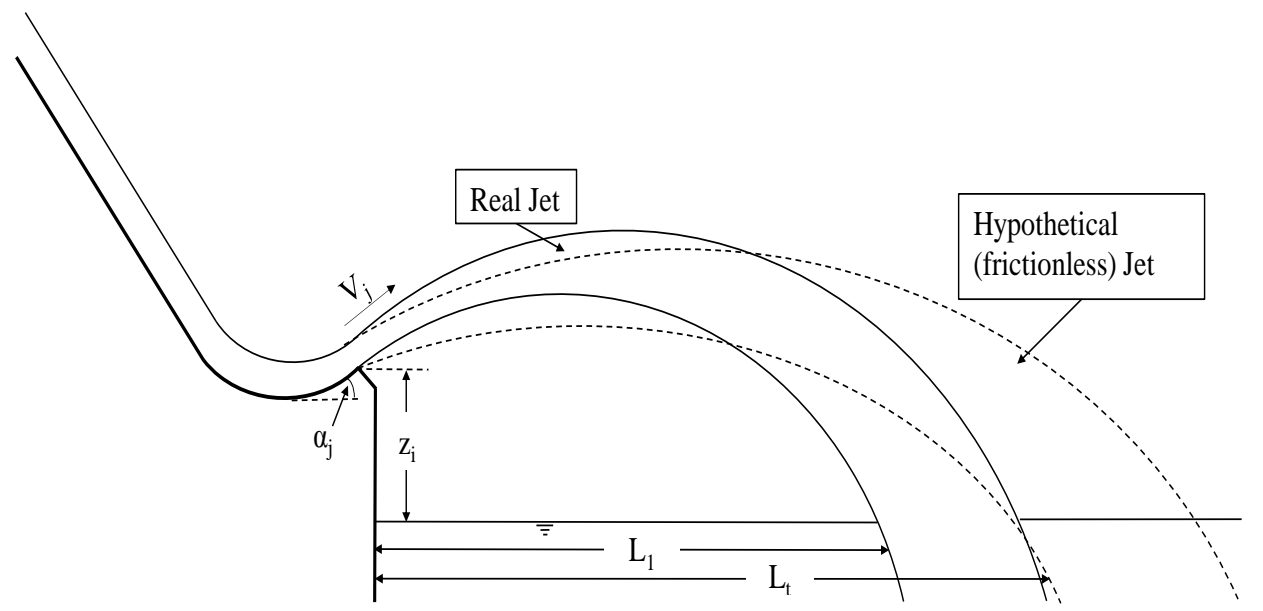

Fig. 5 Throw distance of jet

\section{VI.DYNAMIC PRESSURE CALCULATIONS}

Pressures recorded from electronic transducers represent the total pressure, $\mathrm{P}_{\mathrm{T}}$, composed of mean and fluctuating components. The mean pressure, $\mathrm{P}_{\mathrm{H}}$, in this case is the hydrostatic component independent of time, and $P_{d}$ is the fluctuating component due to large scale turbulence. Subtracting the hydrostatic pressure head from recorded total pressure head, the dynamic pressure head is obtained from Eq. [5].

$\frac{\mathrm{P}_{\mathrm{d}}}{\mathrm{\gamma}}=\frac{\mathrm{P}_{\mathrm{T}}}{\mathrm{p}}-\frac{\mathrm{P}_{\mathrm{H}}}{\mathrm{p}}$

Dynamic pressure variations at the bed for variable water cushion depths and different discharges obtained from the experiments are shown in Fig. 6. 

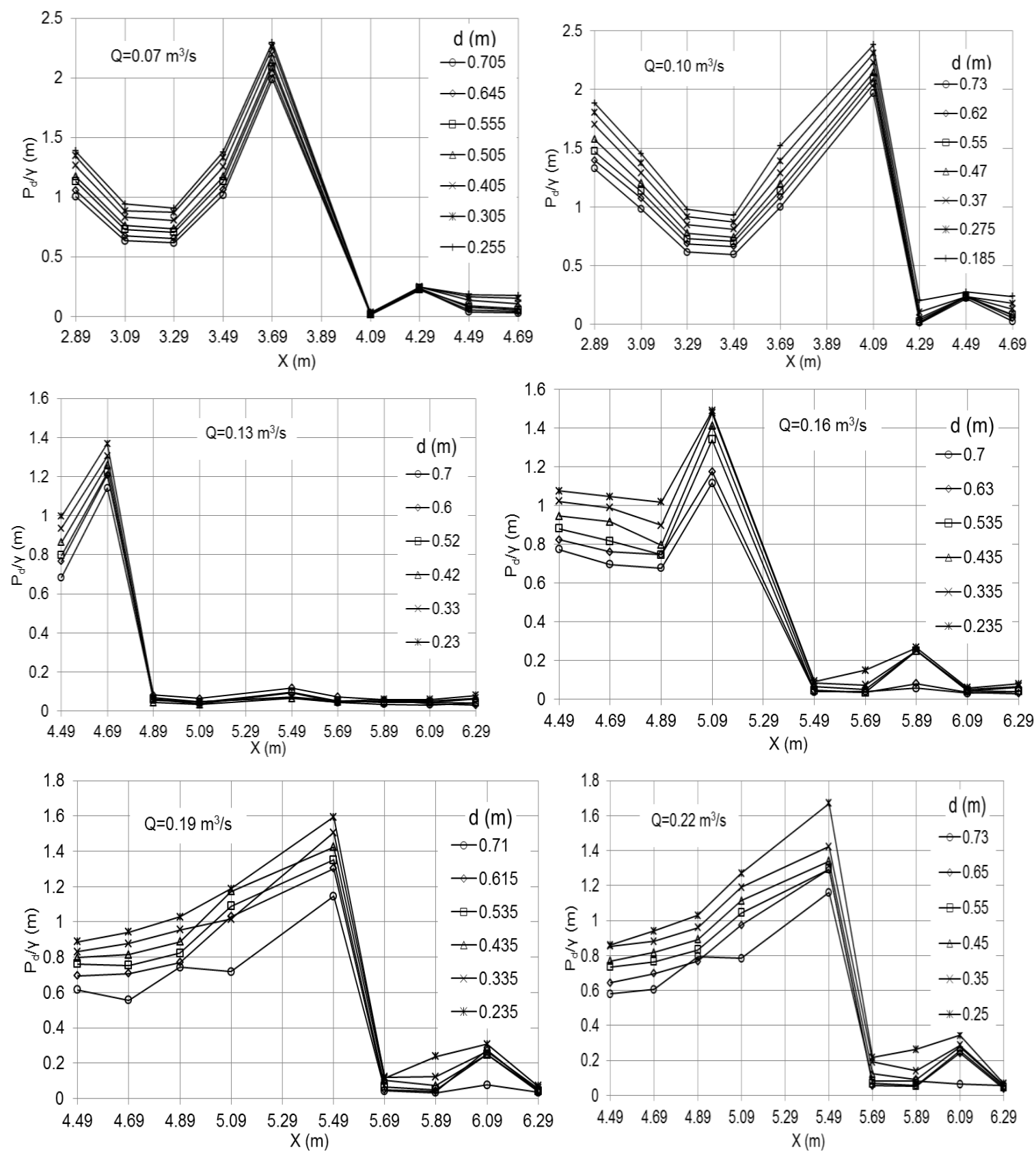

Fig. 6 Dynamic pressure variations due to different water depths for various discharges

If the measured pressure data in Fig. 6 is inspected, it can be seen that increasing the tail water depth in the plunging area reduces the dynamic pressure for a constant discharge up to $0.13 \mathrm{~m}^{3} / \mathrm{s}$. However, dynamic pressures suddenly increase for discharges lower than $0.13 \mathrm{~m}^{3} / \mathrm{s}$. The enhancement of dynamic pressure at low discharges has two reasons: the increased trajectory angle $\left(\alpha_{t}\right)$ at the impingement point and insufficient aeration of the water jet. Experimental data revealed that aeration of the jet is more effective in reducing the dynamic pressures on the river bed rather than increasing the tail-water depth.

\section{VII.ANALYSIS OF RELATIONSHIP BETWEEN EXPERIMENTAL, CALCULATED AND SIMULATED DATA}

a. Comparison of the Measured, Calculated and Simulated Trajectory Lengths

Flip bucket lip angle and the jet velocity on the bucket lip together define the profile of the trajectory. Depending on the projectile motion theory, the water jet motion occurs in a frictionless domain. Therefore, velocity does not change throughout the trajectory of the jet. If a measured trajectory length is compared to the one obtained by assuming that the motion occurs in the frictionless medium, the velocity required to traverse 
this length can be calculated. Since the environment is frictionless, the bucket lip velocity does not change until the impingement point. Difference between the velocities obtained from the measured and calculated (frictionless) lengths gives the head loss due to air entrainment.

Initially, the jet trajectory can be calculated on the basis of projectile theory from Eq. [1] and the trajectory length with air entrainment should be calculated from Eq. [2]. In order to utilize Fig. 4 to define the air resistance/air entrainment constant given by Kawakami, prototype velocities are required. In addition to this calculation, simulations of trajectory lengths by using Flow-3D software are performed for the comparison of the measured and calculated trajectory lengths for the same conditions. Results of the measured trajectory lengths from the experiments, calculated trajectory lengths from projectile theory and Kawakami's equation and numerical results are given in Table 2 .

Table 2 Comparison of the measured, calculated and simulated trajectory lengths

\begin{tabular}{|l|l|l|l|l|l|l|l|}
\hline $\mathrm{V}_{\mathrm{j}}(\mathrm{m} / \mathrm{s})$ & $\left(\mathrm{V}_{\mathrm{j}}\right)_{\text {prototype }}(\mathrm{m} / \mathrm{s})$ & k from Fig. 9 & $\mathrm{~L}_{\mathrm{tc}}(\mathrm{m})$ & $\mathrm{L}_{\mathrm{ts}}(\mathrm{m})$ & $\left(\mathrm{L}_{1}\right)_{\mathrm{m}}(\mathrm{m})$ & $\left(\mathrm{L}_{1}\right)_{\mathrm{c}}(\mathrm{m})$ & $\left(\mathrm{L}_{1}\right)_{\mathrm{s}}(\mathrm{m})$ \\
\hline 7.86 & 39.29 & 0.025 & 7.06 & 6.95 & 5.49 & 5.34 & 5.40 \\
\hline 7.66 & 38.31 & 0.026 & 6.77 & 6.70 & 5.10 & 5.10 & 5.40 \\
\hline 7.41 & 37.04 & 0.022 & 6.41 & 6.15 & 5.04 & 4.78 & 4.85 \\
\hline 7.07 & 35.33 & 0.021 & 5.95 & 5.90 & 4.67 & 4.36 & 4.60 \\
\hline 6.58 & 32.89 & 0.020 & 5.32 & 5.30 & 4.07 & 3.79 & 4.40 \\
\hline 5.83 & 29.17 & 0.020 & 4.42 & 4.20 & 3.55 & 2.98 & 3.83 \\
\hline
\end{tabular}

In Table 2, $\left(\mathrm{L}_{t}\right)_{\mathrm{c}}$ and $\left(\mathrm{L}_{\mathrm{t}}\right)_{\mathrm{s}}$ is the calculated and simulated trajectory lengths without air entrainment and $\left(\mathrm{L}_{1}\right)_{\mathrm{m}},\left(\mathrm{L}_{1}\right)_{\mathrm{c}}$ and $\left(\mathrm{L}_{1}\right)_{\mathrm{s}}$ is the measured, calculated and simulated trajectory lengths with air entrainment respectively. As can be seen from the Table, calculated trajectory lengths using projectile motion formula and the simulated trajectory lengths using Flow-3D software without considering air entrainment are almost matching up with each other. On the other hand, measured, calculated and simulated trajectory lengths considering air entrainment show small variations in the range of experimental accuracy. Since both analytical and numerical methods give similar results with the experimental measurements, head losses due to air entrainment in water jets can be estimated using either analytical methods or numerical approaches as well. So, numerical simulations are also performed for non-aerated medium. But, measured trajectory lengths and calculated trajectories using Kawakami's formula are reduced by significant amount of air absorbed which turned the water jet into air-water mixture. Aerated jet trajectories can be obtained by using CFD solution as well. Since the aerated trajectory lengths can be measured only from the test facility, comparing these lengths can be more appropriate to see the difference between the measured, calculated and simulated trajectories. Comparison of the measured, calculated and simulated trajectory lengths with air entrainment are shown in Fig. 7.
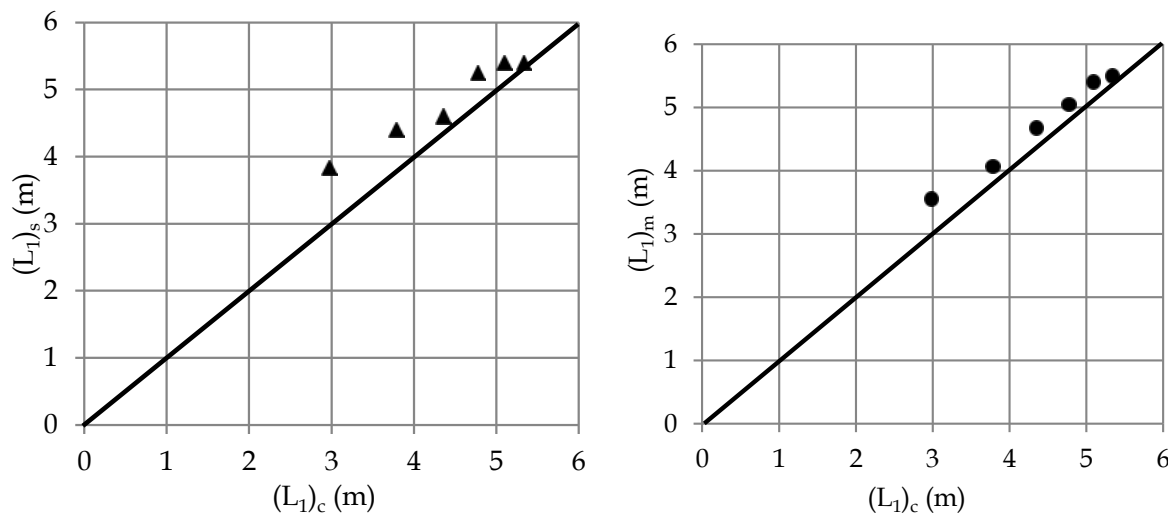

Fig. 7 Comparison of the measured, calculated and simulated trajectory lengths with air entrainment

When the arbitrariness in measurement and the difference between the equations in calculating and simulating the trajectory length for this study is considered, the agreement is assumed to be good.

\section{b. Calculation of Head Loss Due to Air Entrainment}

Fig. 7 shows that the measured, calculated and simulated trajectory lengths are very close. In order not to perform any experiment and refrain from the uncertainty of the empirical equations, calculation of head loss due to air entrainment can be reasonable via calculating the velocity difference considering the trajectory lengths by neglecting the air entrainment from numerical results. Head losses due to air entrainment can then be calculated depending on the simulated trajectory lengths. Initially simulated trajectory lengths without air entrainment are used to obtain required jet velocities using Eq. [1]. Same calculations are made on the simulated 
lengths by including the air entrainment. Head loss value is calculated using the velocity head difference between calculations from Eq. [4]. Head loss calculations are given in Table 3 for the test cases.

Table 3 Head loss due to air entrainment

\begin{tabular}{|l|l|l|l|l|l|}
\hline $\mathrm{Q}\left(\mathrm{m}^{3} / \mathrm{s}\right)$ & $\mathrm{V}_{\mathrm{j}}(\mathrm{m} / \mathrm{s})$ & $\mathrm{V}_{\mathrm{j} 2}(\mathrm{~m} / \mathrm{s})$ & $\mathrm{H}_{\mathrm{j}}(\mathrm{m})$ & $\mathrm{H}_{\mathrm{j} 2}(\mathrm{~m})$ & $\mathrm{h}_{\mathrm{L}}(\mathrm{m})$ \\
\hline 0.22 & 7.79 & 6.65 & 3.09 & 2.25 & 0.84 \\
\hline 0.19 & 7.62 & 6.65 & 2.96 & 2.25 & 0.71 \\
\hline 0.16 & 7.22 & 6.20 & 2.65 & 1.96 & 0.69 \\
\hline 0.13 & 7.03 & 5.99 & 2.52 & 1.83 & 0.69 \\
\hline 0.10 & 6.57 & 5.82 & 2.20 & 1.73 & 0.47 \\
\hline 0.07 & 5.64 & 5.30 & 1.62 & 1.43 & 0.19 \\
\hline
\end{tabular}

\section{c.Evaluation of Measured Dynamic Pressure Data}

The maximum measured dynamic pressure values are shown as function of discharge in Fig. 8. When the measured maximum dynamic pressure values are inspected carefully, it is observed that dynamic pressure decreases with decreasing discharge. However, below a critical value, there is a sharp increase in dynamic pressure. This result is due to reduced rate of aeration with less air bubbles penetrating the water body at the impingement area. The sudden change in air bubble formation may be due to scale effect in the laboratory where the Reynolds and Weber numbers may be small for small discharges used in the experiments. In order to avoid scale effect in aerated flow, the Reynolds number of the jet flow should be above $3 \times 10^{5}$ and Weber number of the jet flow should be above $2 \times 10^{4}$ for similar studies [17]. The measured dynamic pressures for the first two test cases $\left(0.07\right.$ and $\left.0.10 \mathrm{~m}^{3} / \mathrm{s}\right)$ are significantly larger indicating that aeration of the water cushion body was not sufficient for those test cases. Reynolds and Weber number values of the test cases are shown in Fig. 9 and Fig. 10.

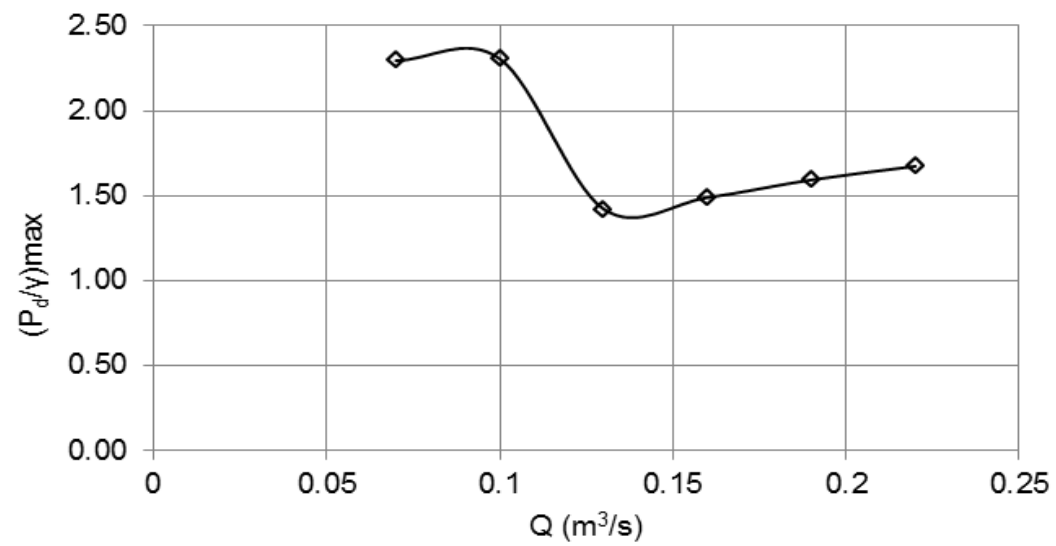

Fig. 8 Dynamic pressure variations with respect to water discharge

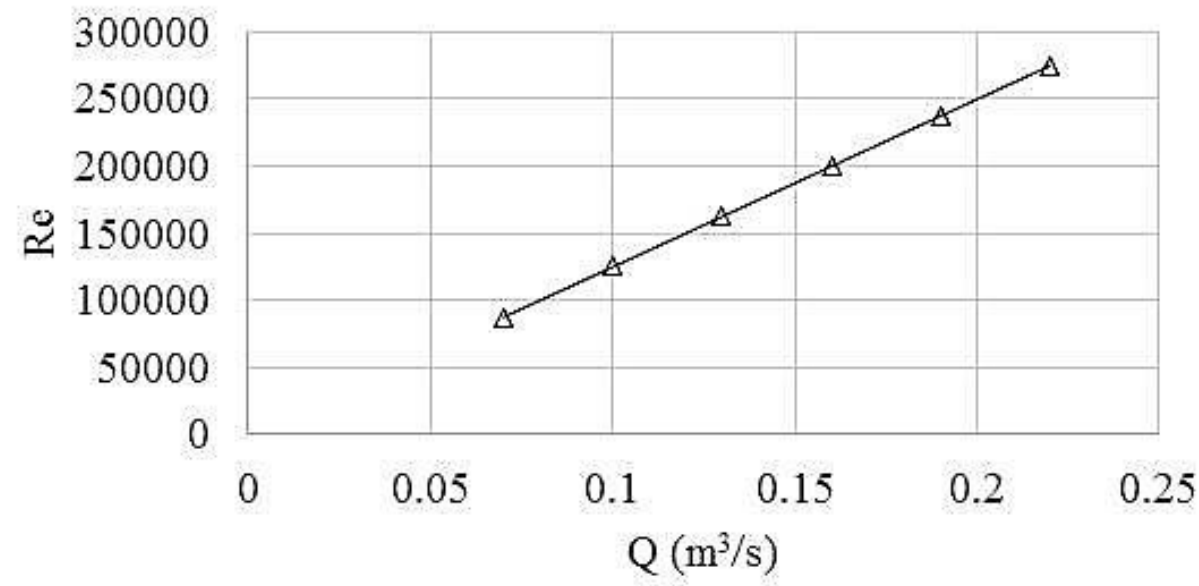

Fig. 9 Reynolds number as function of discharge 


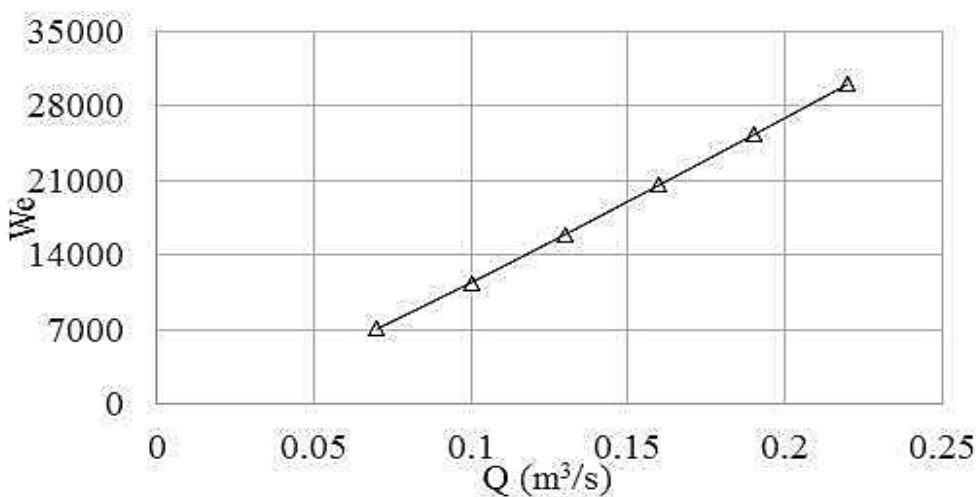

Fig. 10 Weber number as function of discharge

The measured and numerical dynamic pressure heads are normalized by the total head $\left(\mathrm{P}^{+}\right)$and drawn against the dimensionless tail water depth, $\mathrm{d}^{+}$normalized with the total head $\mathrm{H}_{\mathrm{T}}$ at the bucket lip. The comparisons of the results are shown in Fig. 11.

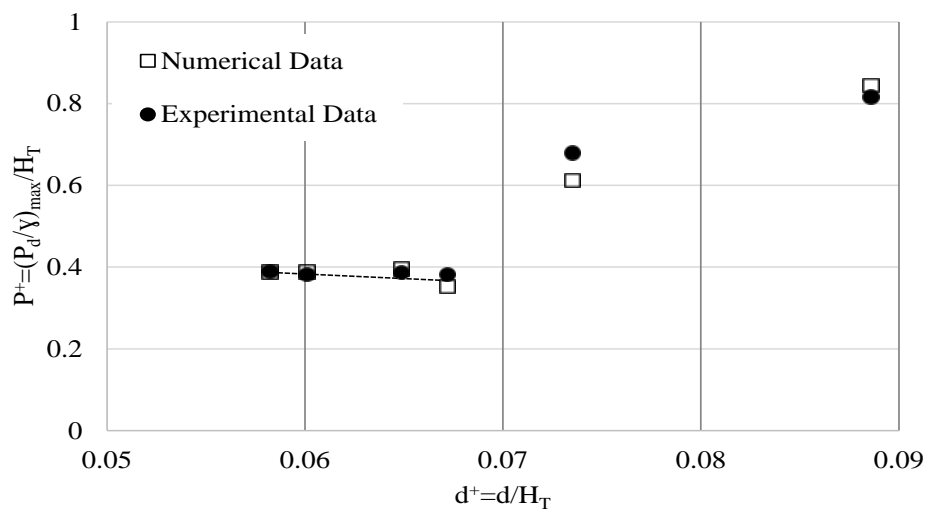

Fig. 11 Comparison of the measured and numerical maximum dynamic pressures to total head ratio as function of tail water depth to total head ratio

It is obvious that the measured values of the first two test cases are considerably different than the other four test cases with larger discharges. As discussed above, this is an indication of insufficient aeration in the model. Therefore, they will not be considered as valid data to discuss the water cushion effect. The measured dynamic pressure head data for discharges $0.13,0.16,0.19$ and $0.22 \mathrm{~m}^{3} / \mathrm{s}$ collapses on to the same line for which a functional representation can be given. The best fit line for the dimensionless dynamic pressure $\left(\mathrm{P}^{+}\right)$is written in terms of dimensionless water depth $\left(\mathrm{d}^{+}\right)$

$\mathrm{P}^{+}=-2.834\left(\mathrm{~d}^{+}\right)+0.5585$

Equation [6] can be used to predict dynamic pressures from assumed tailwater depths.

\section{VIII.CONCLUSIONS}

In the present study impact of water jet from a flip bucket on the impingement point on the river bed has been studied. Effects of aeration and water depth at the impingement point on the dynamic pressures were investigated experimentally. Empirical equations were used to calculate the jet trajectory lengths with and without air entrainment. The computed trajectory lengths were compared to measured ones for the six different test discharges. From this experimental study, the following conclusions can be drawn:

1)Dynamic pressure is not directly proportional to the water discharge coming from the flip bucket. The trajectory angle and the amount of air entrainment are important quantities for the impact assessment of the jet at the downstream of the flip bucket.

2)Air entrainment affects the trajectory length and trajectory angle at the impingement point which is more effective in energy dissipation than the tail water depth.

3)An expression (Eq.6) for predicting the dynamic pressures at the impingement point is developed as a function of dimensionless tail water depth.

4)A significant increase in dynamic pressures were observed for jet discharges less than $0.130 \mathrm{~m}^{3} / \mathrm{s}$ for which Weber number goes below $2 \times 10^{4}$ This behavior was partly attributed to less air bubble penetration into the 
water cushion a result of scale effect specific to the present experimental set-up. This situation would not occur in real structures since the Weber numbers are expected to be larger than the limiting value.

5)For decreasing discharges the trajectory angle at the impingement area increases which also increases the jet impact and therefore dynamic pressures. The maximum discharge may not produce the maximum dynamic pressures. Therefore, discharges smaller than the maximum should also be considered in the analysis and design stages of the flip bucket type energy dissipaters.

6)Head loss due to air entrainment between the bucket lip and impingement point can be determined using both analytical and numerical methods as demonstrated in this study.

7) Acknowledgement

8) The authors want to appreciate the cooperation and efforts of Prof. Dr. Mustafa M. Aral in completion of this study.

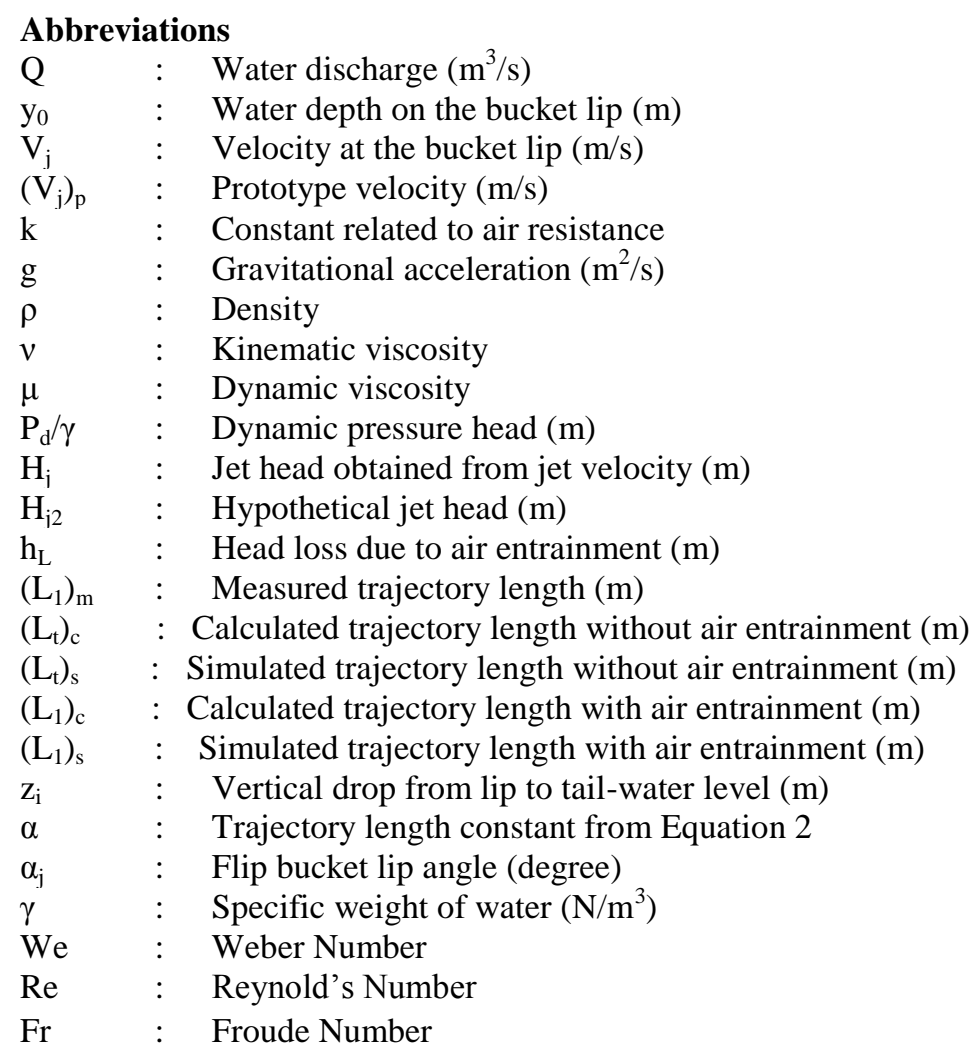

\section{REFERENCES}

[1].Godon, R. (1936). “Le barrage et l'usine hydro-e'lectrique de Mare'ges, sur la Dordogne.' Techniques des Travaux, 12, 101-110 (in French).

[2].Coyne, A. (1944). “Prototypes modernes de barrages et d'usines hydroe'lectriques." Travaux, 28, 25-29 (in French).

[3].Coyne, A. (1951). “'Observations sur les de'versoirs en saut de ski.” Proc., 4th ICOLD Congr., Vol. Q12, R89, 737-756 (in French).

[4].Auroy, F. (1951). "Les e'vacuateurs de crues du barrage de Chastang." Proc., 4th ICOLD Congr., Vol. Q12, R82, 661-686 (in French).

[5].Maitre, R., and Obolensky, S. (1954). "Etude de quelques caracte'ristiques de l'e'coulement dans la partie aval des e'vacuateurs de surface.' La Houille Blanche, Grenoble, France, 9(7), 481-511 (in French).

[6].Rajan, B. H., and Shivashankara Rao, K. N. (1980). "Design of trajectory buckets.” J. Irrig. Power India, 37(1), 63-76, ISSN: 0974-4711

[7].Heller, V., Hager, W. H., and Minor, H.E. (2005). Ski jump hydraulics. J. Hydraul. Eng., 131(5), 347-355, DOI: 10.1061/(ASCE)07339429(2005)131:5(347)

[8].Mason, P. J. (1989) Effect of air entrainment on plunge pool scour. ASCE Jrnl. of Hyd. Eng. 385-399. DOI: 10.1061/(ASCE)07339429(1989)115:3(385)

[9].Aydin, I., Göğüş, M., Altan-Sakarya A.B., Köken M. (2012). Laleli Dam and HEPP Spillway Hydraulic Model Studies. Hydromechanics Laboratory, Civil Engineering Department, METU.

[10].Yavuz C. (2014). Impact Assessment of Water Jets from Flip Buckets, Ms. Thesis, METU, Available at: http://etd.lib.metu.edu.tr/upload/12617698/index.pdf

[11].Data Acquisition (DAQ) Software retrieved from: http://turkey.ni.com/

[12].Khatsuria, R. M. (2005). Hydraulics of Spillways and Energy Dissipators, CRC Press, Taylor \& Francis Group, NW, ISBN: 978-0-20399698-0

[13].Kawakami K. (1973). A Study of the Computation of Horizontal Distance of Jet Issued from Ski-Jump Spillway.” Proc. of the JSCE, Vol. 219, No. 11, 37-44, DOI: 10.2208/jscej1969.1973.219_37

[14].Flow 3D. (2012). v10.1 User Manuel, Available at:http://www.easysimulation.com/public/flow3dcast/documentation/FLOW3D_Cast_3.2_Manual.pdf 
[15].Launder, B.E., Spalding, D.B. (1974). "The numerical computation of turbulent flows." Computer Methods in Applied Mechanics and Engng. 3(2), 269-289, DOI: 10.1016/0045-7825(74)90029-2

[16].AutoCad Software Available at: http://www.autodesk.com/products/autocad-lt/overview

[17].Pfister M. And Chanson H. (2012) ‘Discussion: Scale effects in physical hydraulic engineering models', Journal of Hydraulic Research, 50(2):244-246.DOI: 10.1080/00221686.2012.654671 